\title{
How variations in the rates of effusive basaltic flood volcanism versus \\ aerosol-forming explosive volcanism have driven climate change and rates of mass extinction throughout Earth history
}

Effusive basaltic $2 \times(x)+2$

\section{Peter L. Ward}

United States Geological Survey retired

peward@Wyoming.com

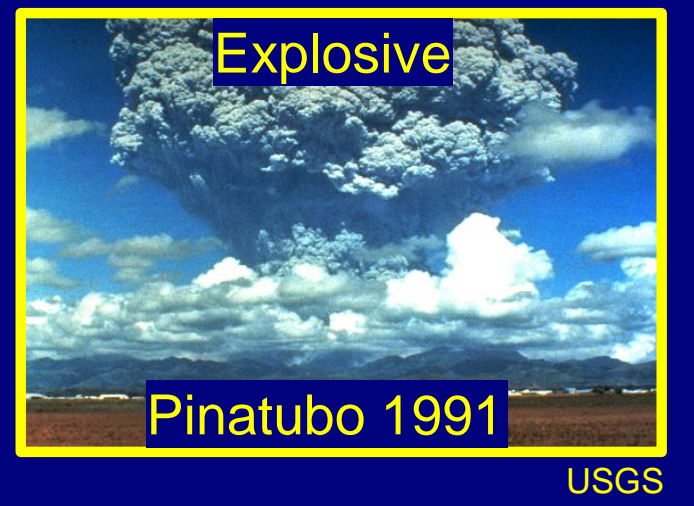




\section{Basaltic volcanism warmed the world out of the last ice age}

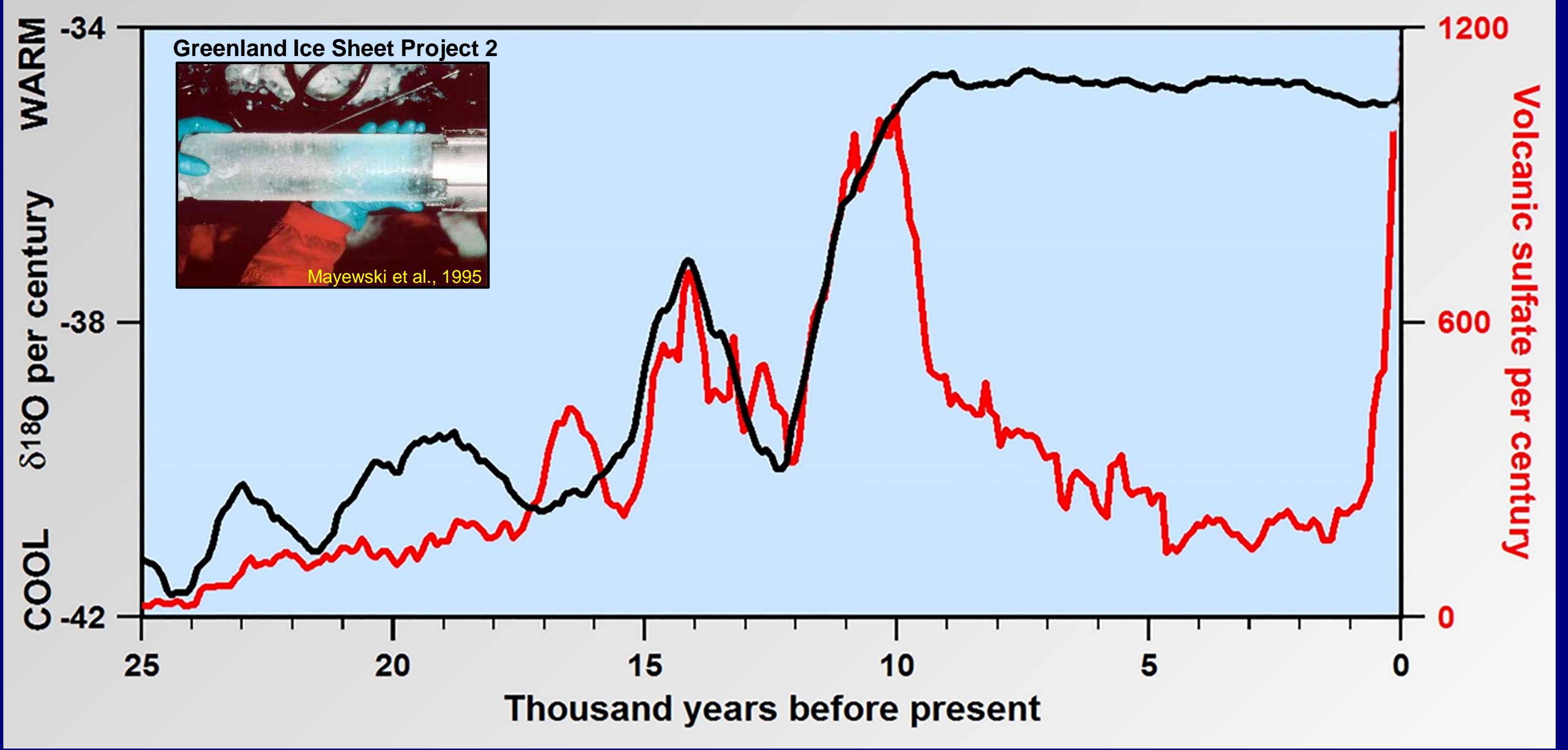




\section{Basaltic volcanism warmed the world out of the last ice age}

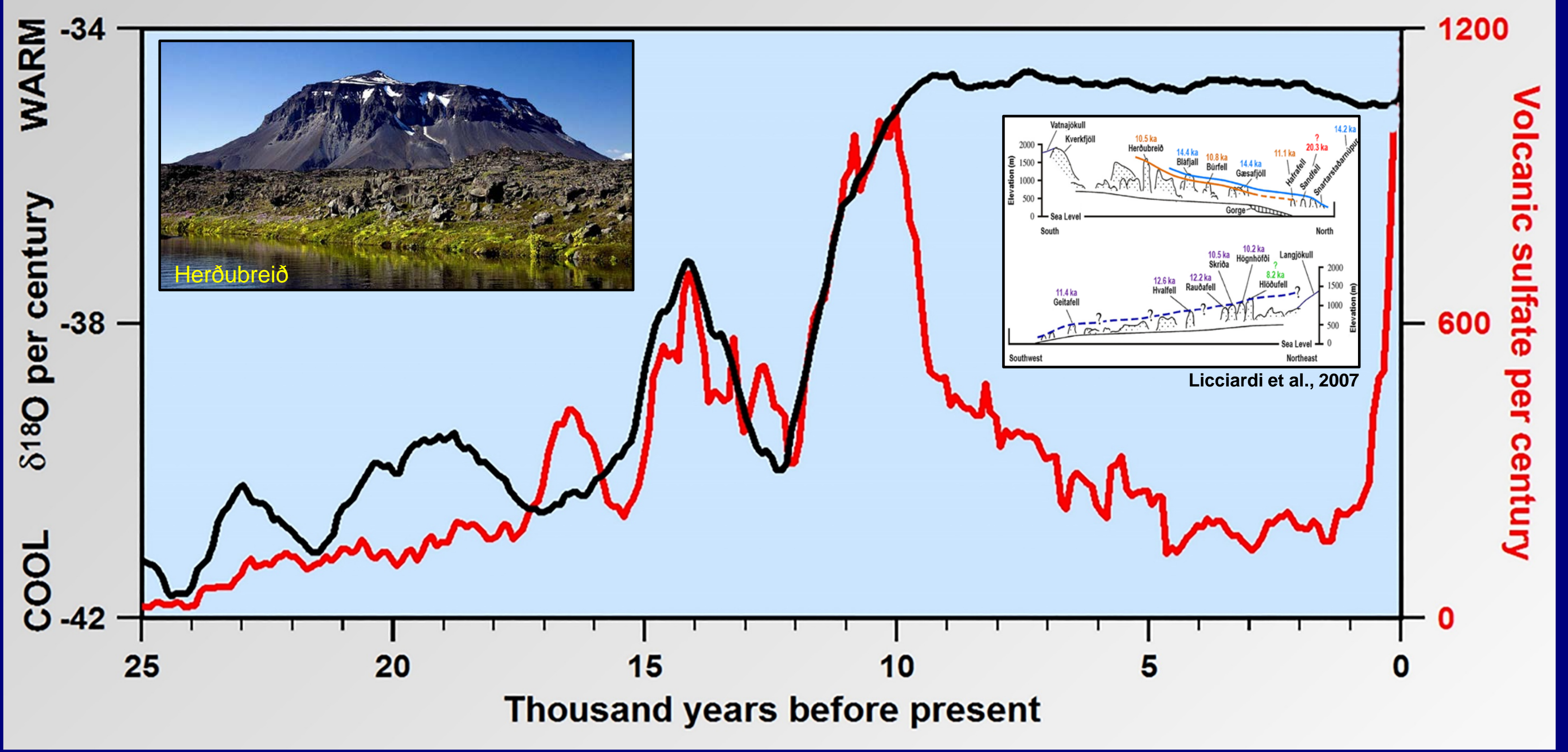




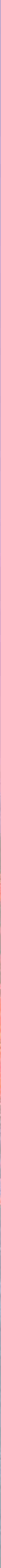


In only 6 months, it oozed basaltic lava over an area of $85 \mathrm{~km}^{2}$, the size of Manhattan

A rate more than 30 times higher than observed in Hawaii

This was the highest rate of basalt extrusion since the eruption of Laki in 1783 


\section{Laki 1783}

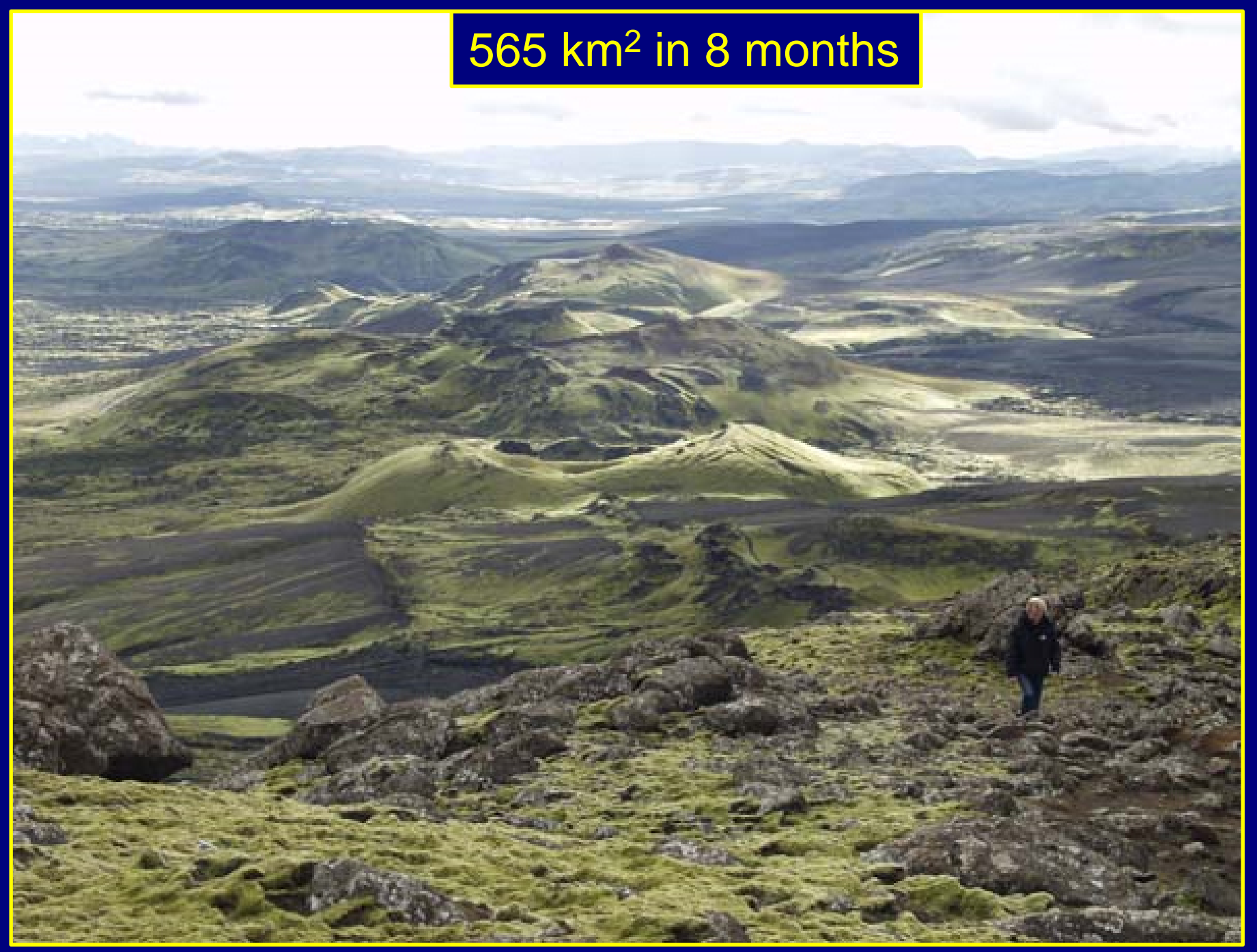

Temperatures raised $3.3^{\circ} \mathrm{C}$, tens of thousands killed primarily by the effects of sulfuric acid 


\section{Laki 1783}

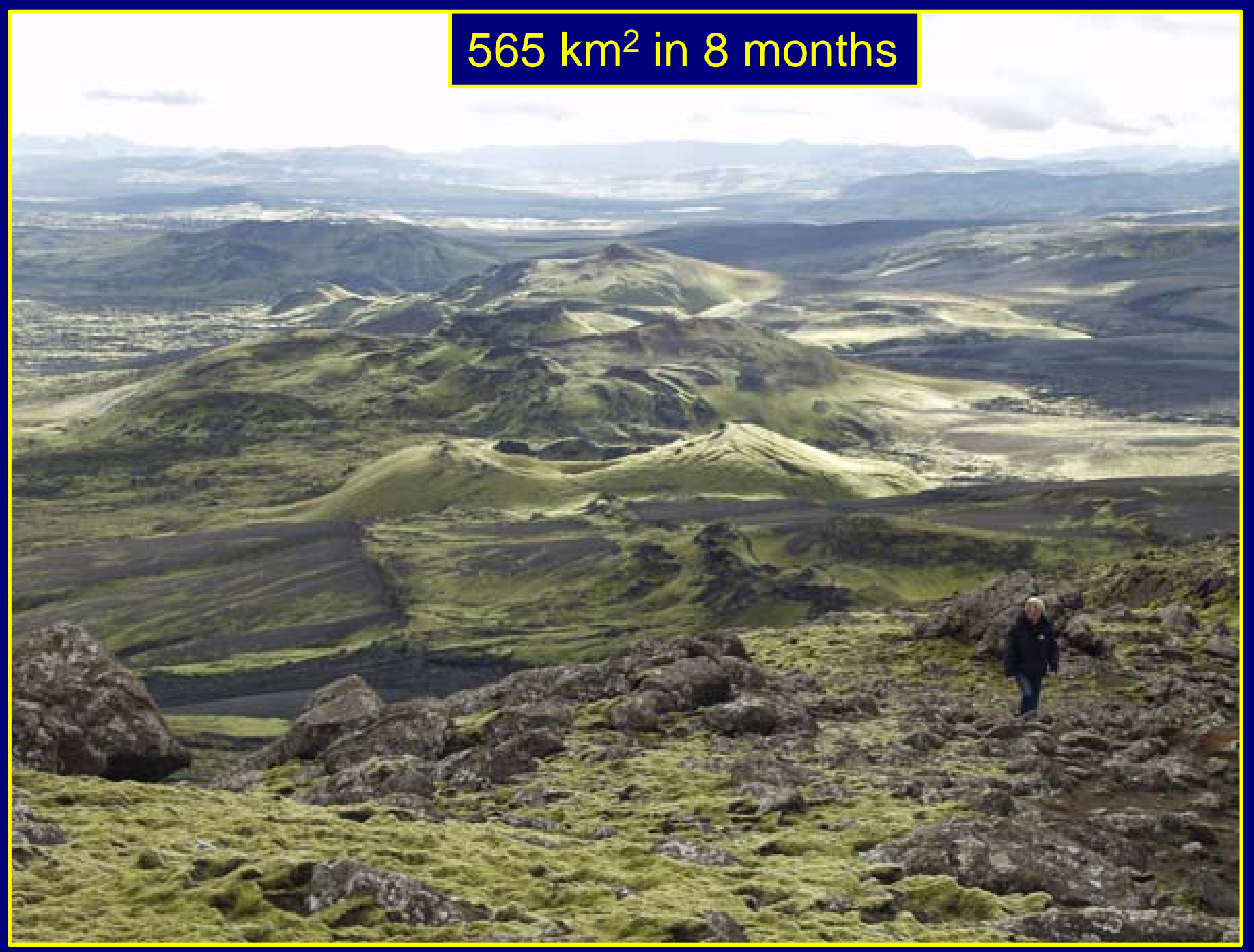

Temperatures raised $3.3^{\circ} \mathrm{C}$, tens of thousands killed primarily by the effects of sulfuric acid
Eldgjá 935

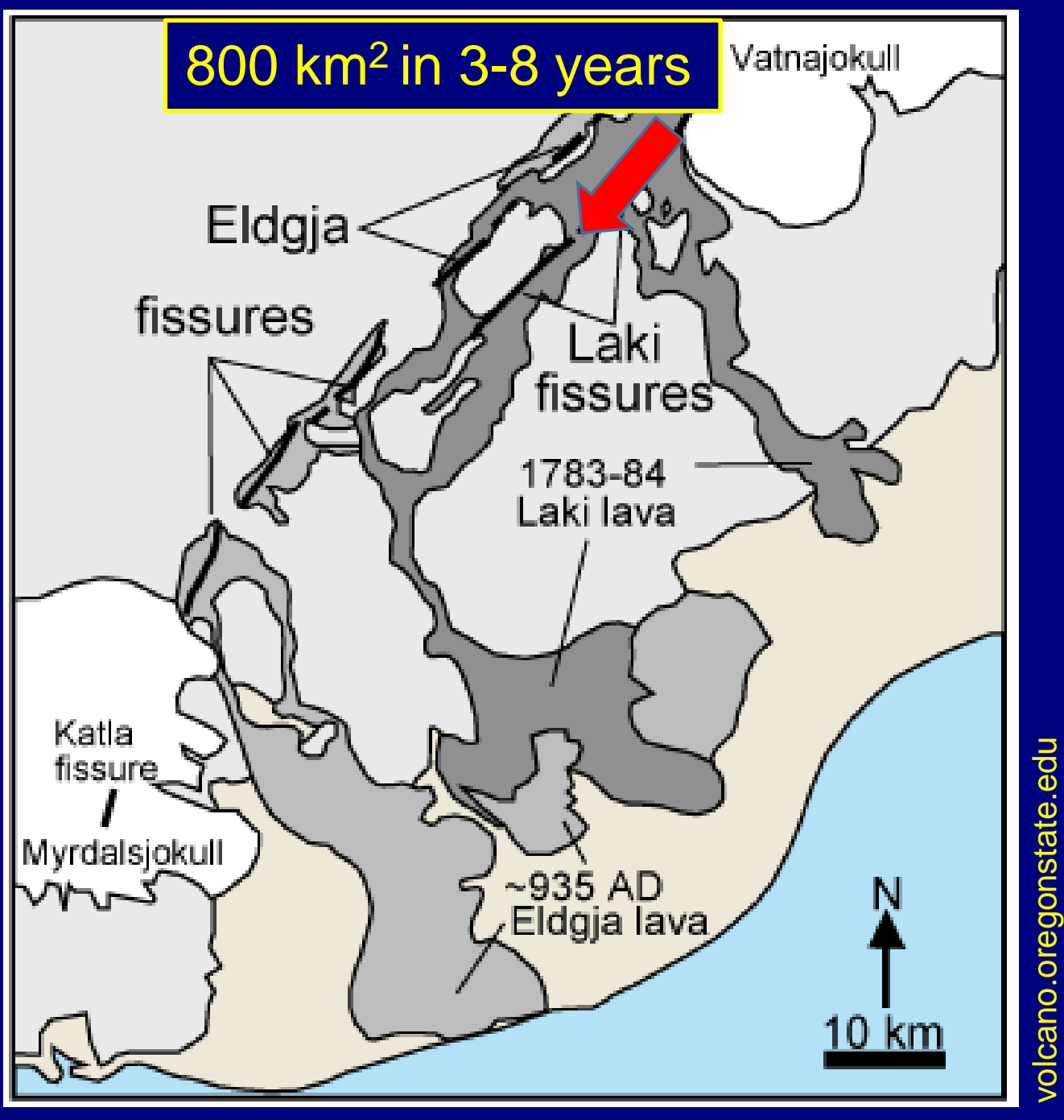

Led to the onset of the Medieval Warm Period 


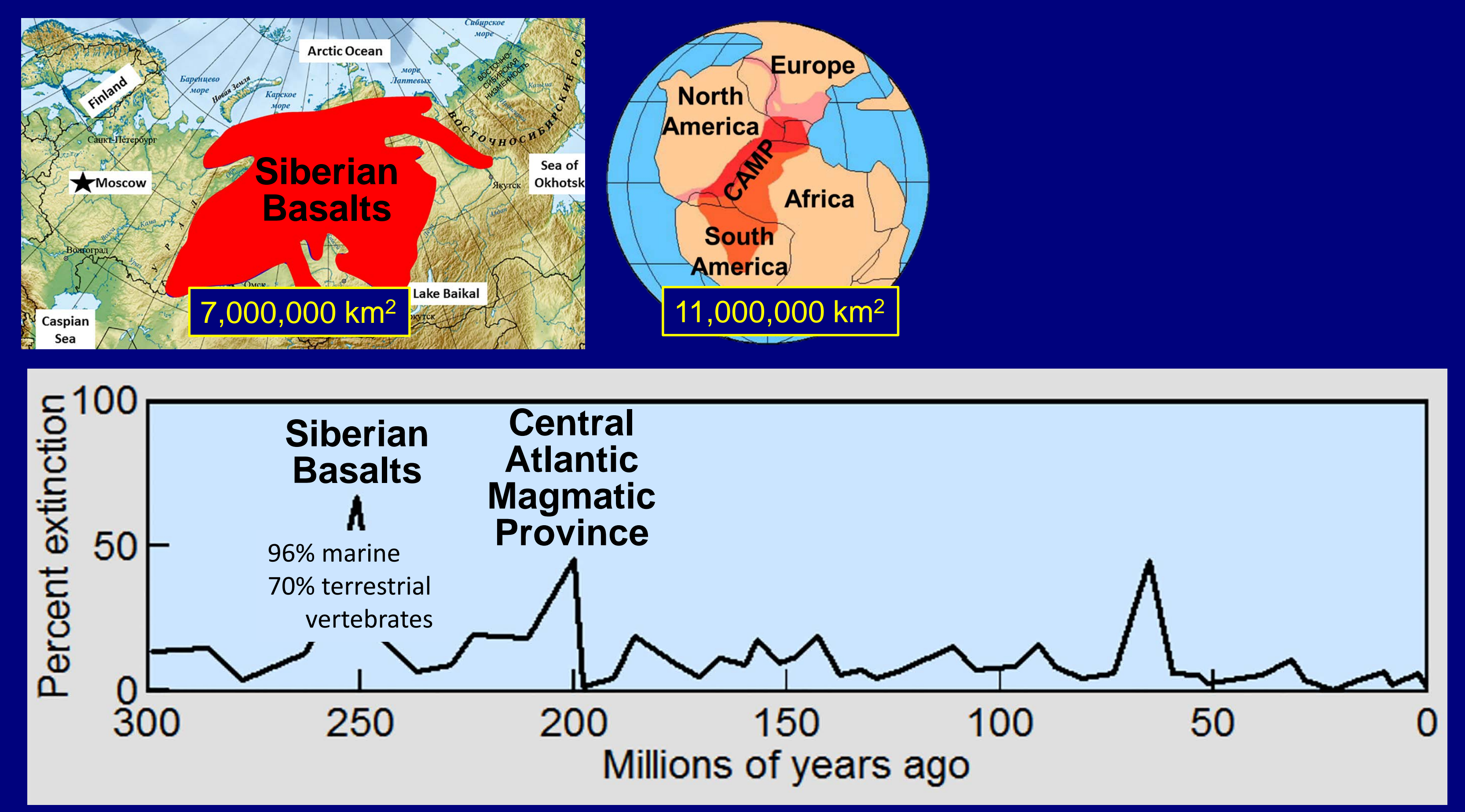




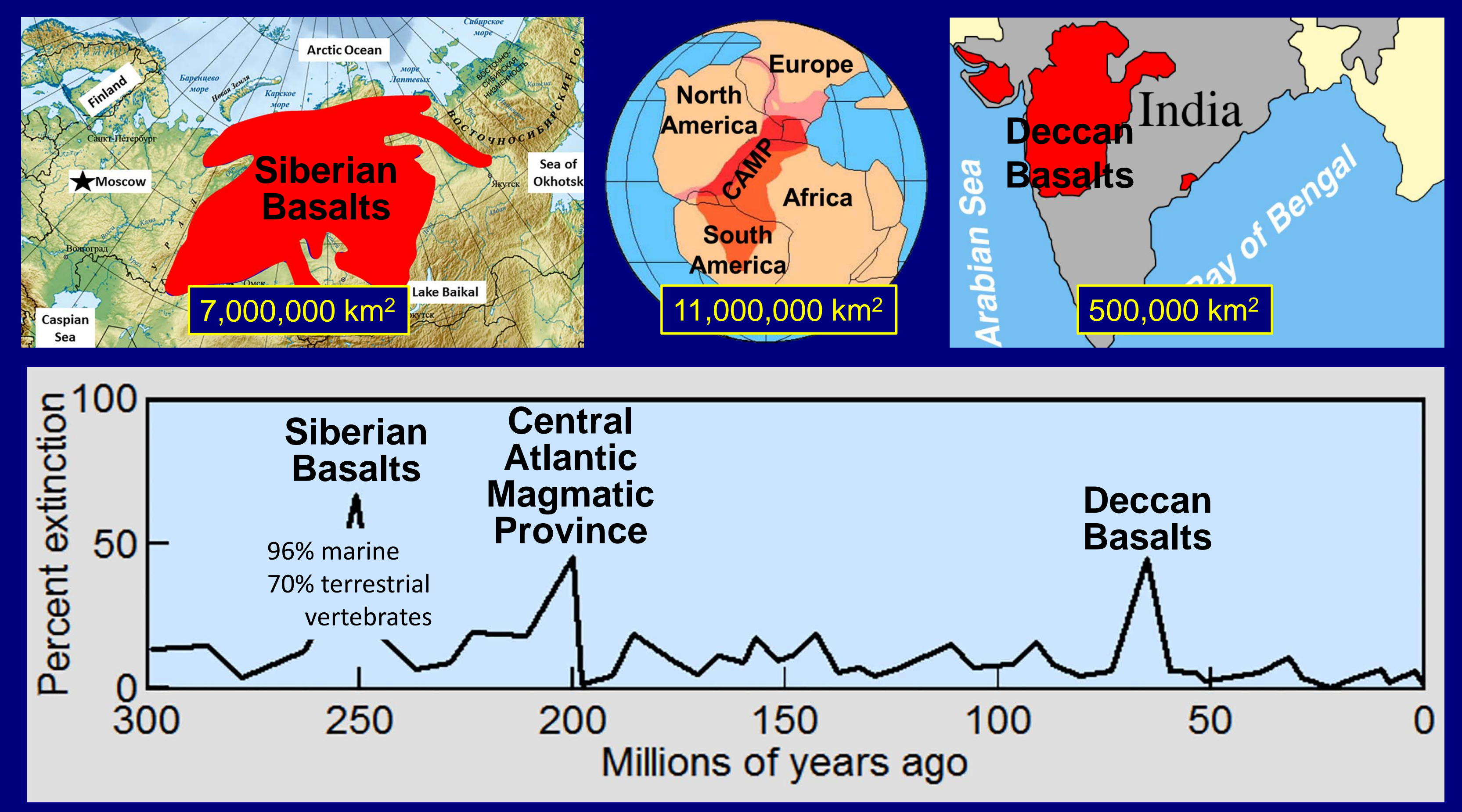




\section{Mass extinctions versus flood basalts}

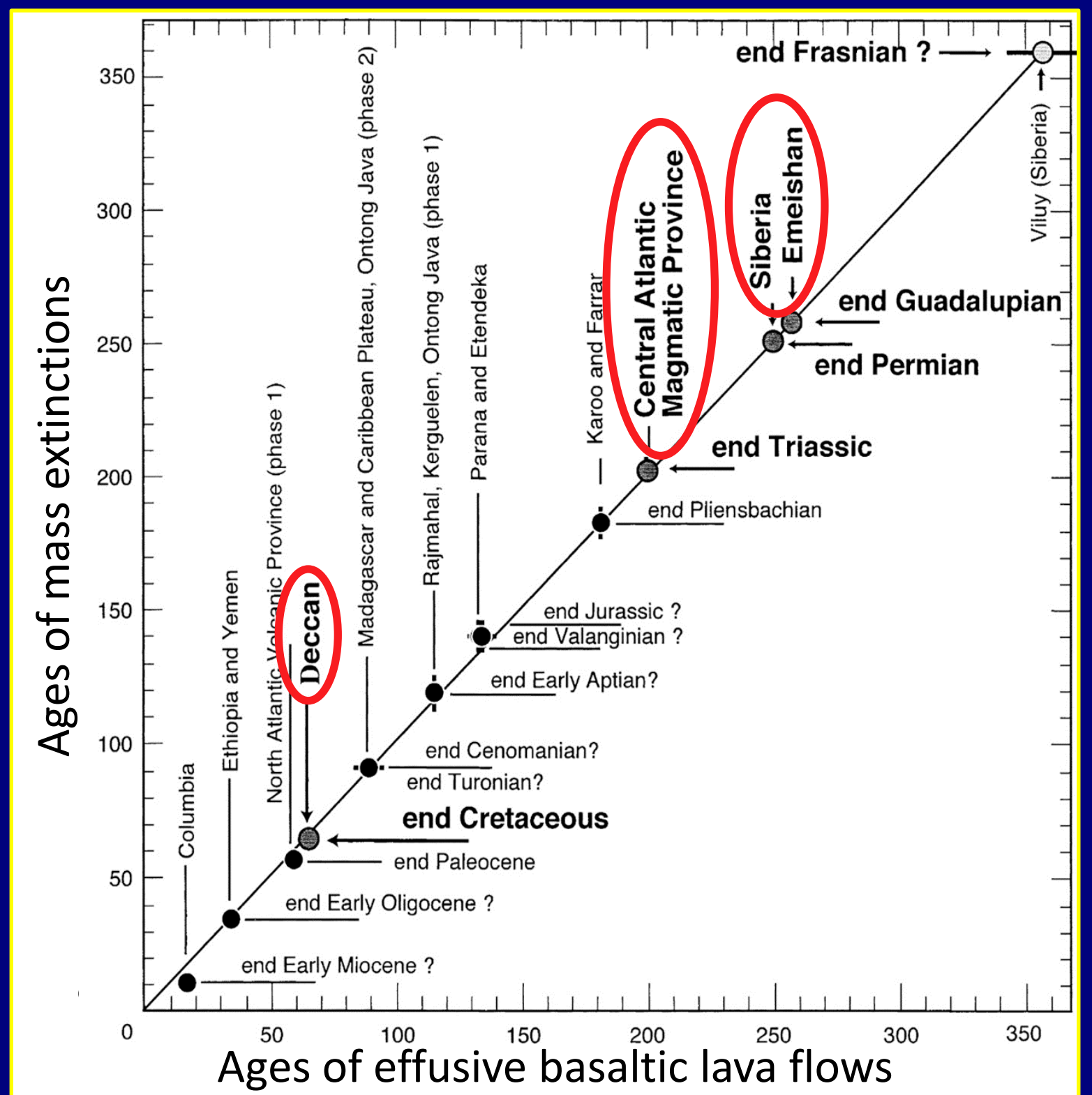

Courtillot and Renne 2003 


\section{Mass extinctions versus flood basalts}

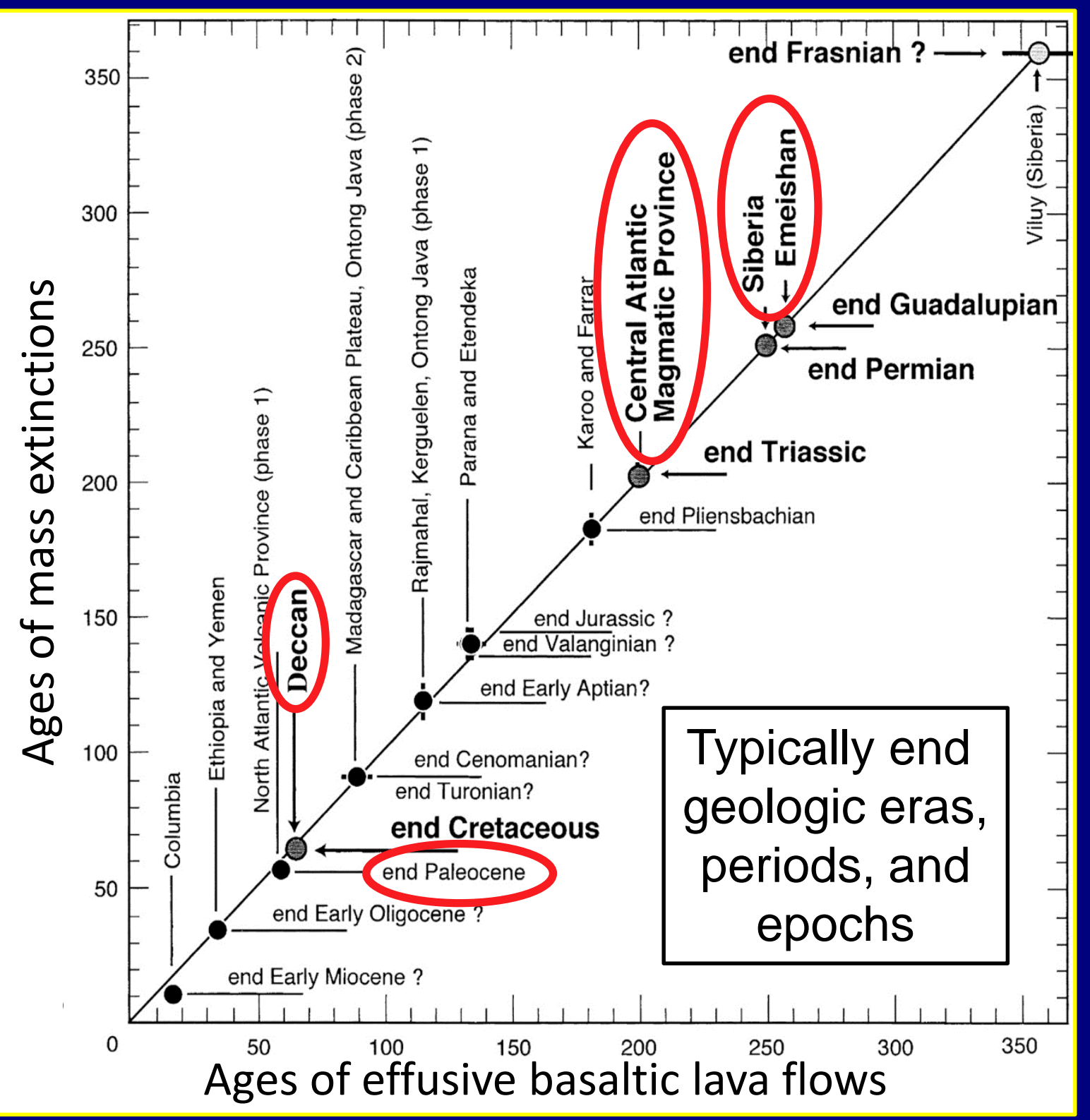

\section{Paleocene Eocene} Thermal Maximum

Extrusion of basaltic magma reached a peak 56 million years ago during the rifting of the GreenlandNorwegian Sea
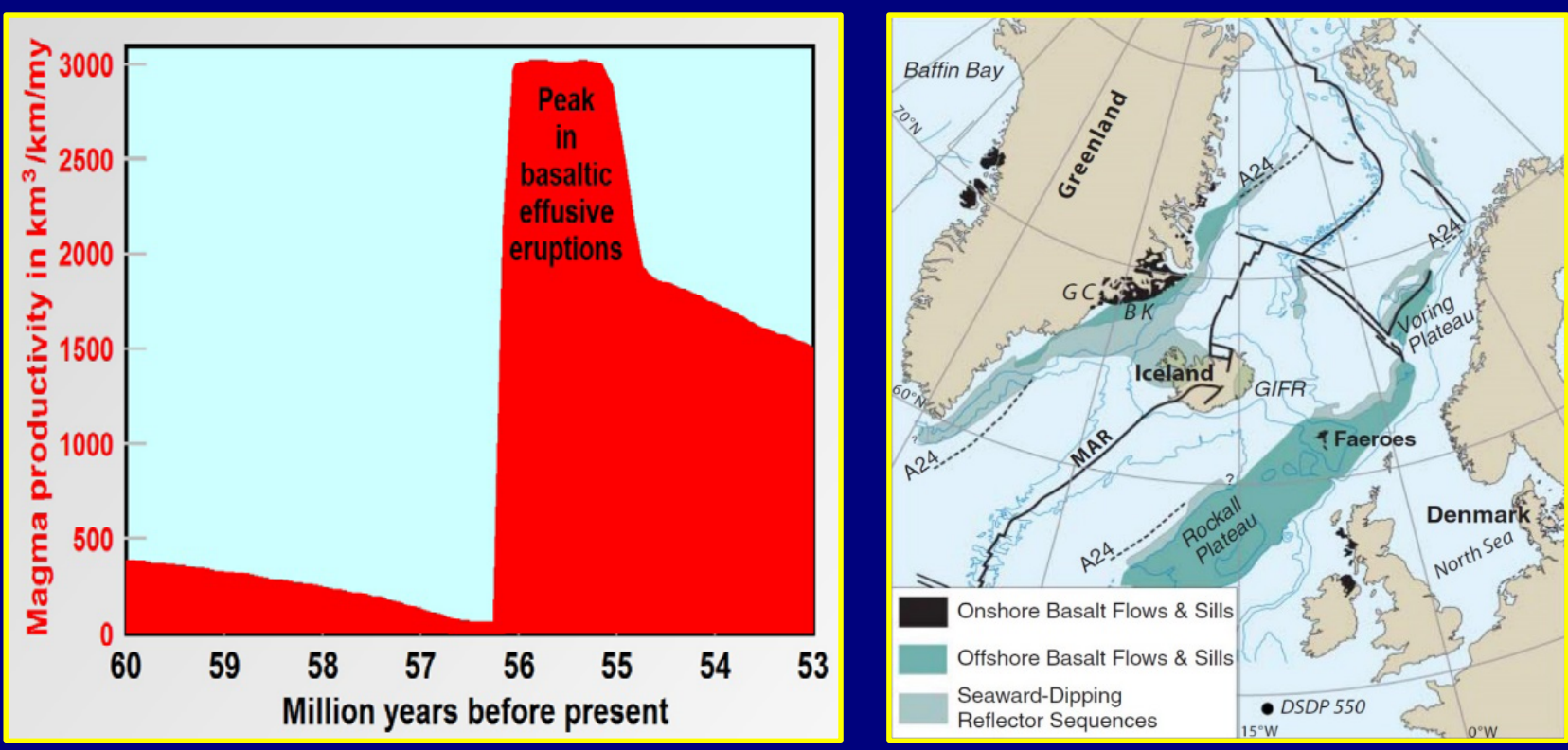
Rift-related, effusive, basaltic, volcanic eruptions warm Earth suddenly

Extrude basaltic lava for months to hundreds of thousands of years

The greater the duration, the greater the warming and extinctions

Range in size from Hawaii to Large Igneous Provinces

Cause major warming of air and, over millennia, of oceans

Cause major ocean acidity (sulfuric acid from $\mathrm{SO}_{2}$ and $\mathrm{H}_{2} \mathrm{~S}$ )

Cause major mass extinctions especially when lasting for long periods

Bárðarbunga largest since 1783-explains why 2016 hottest year 


\section{A fundamentally different type of volcanic eruption}

Subduction-related, explosive, volcanic eruptions cool Earth incrementally over centuries

Erupt for days, may recur within 500 to 1000 years Deplete ozone causing short-term warming

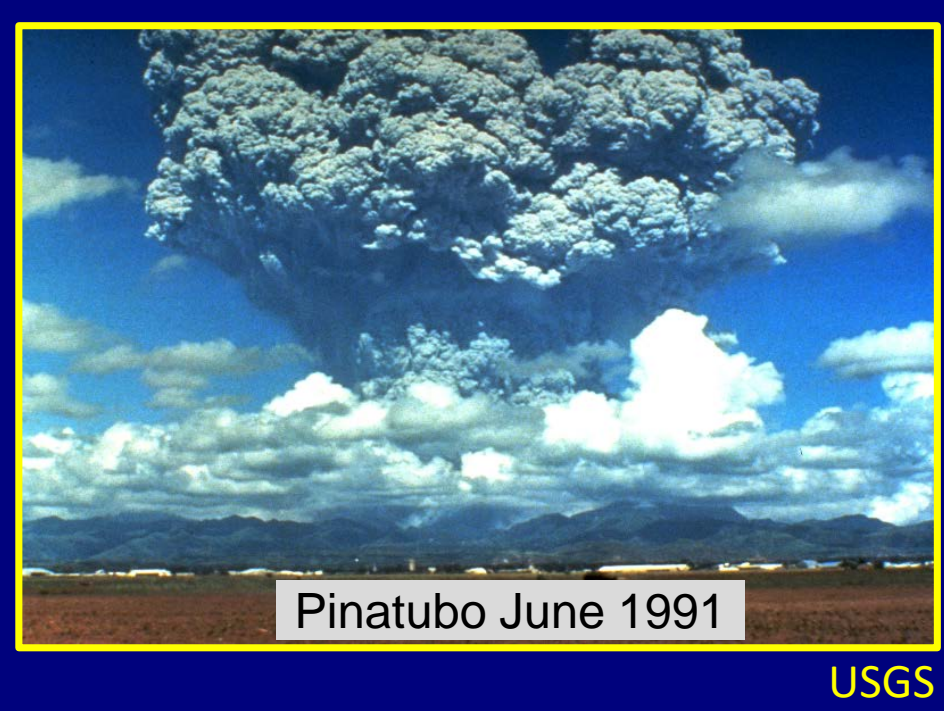

Pinatubo warmed $3.5^{\circ} \mathrm{C}$

Dec 1991 to Feb 1992

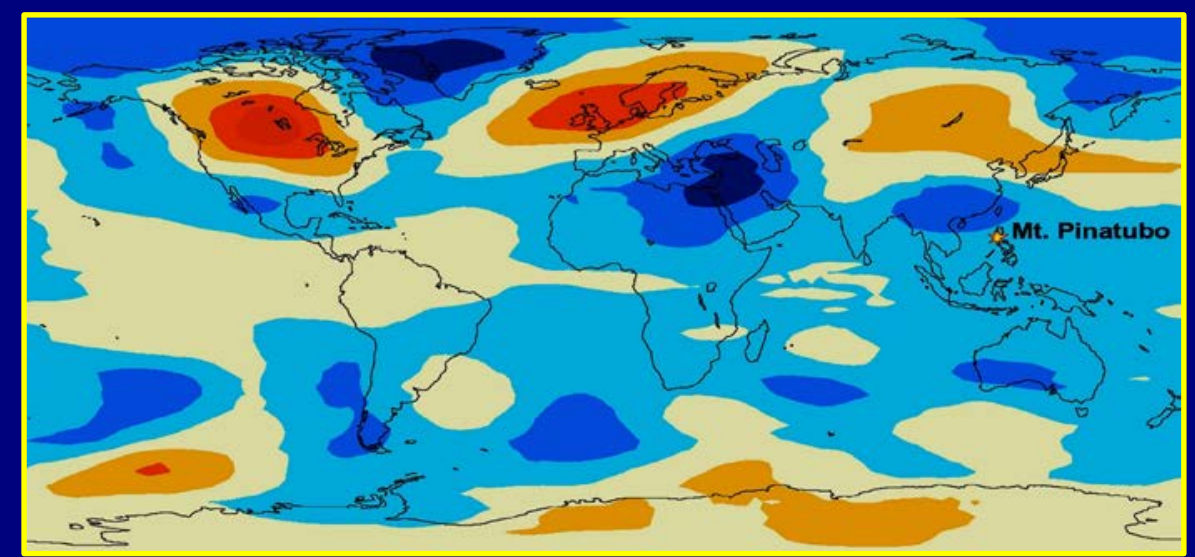




\section{A fundamentally different type of volcanic eruption}

Subduction-related, explosive, volcanic eruptions cool Earth incrementally over centuries

Erupt for days, may recur within 500 to 1000 years Deplete ozone causing short-term warming

Form aerosols in the lower stratosphere that last for years, scattering and reflecting solar energy, causing net global cooling $0.5^{\circ} \mathrm{C}, 3$ years

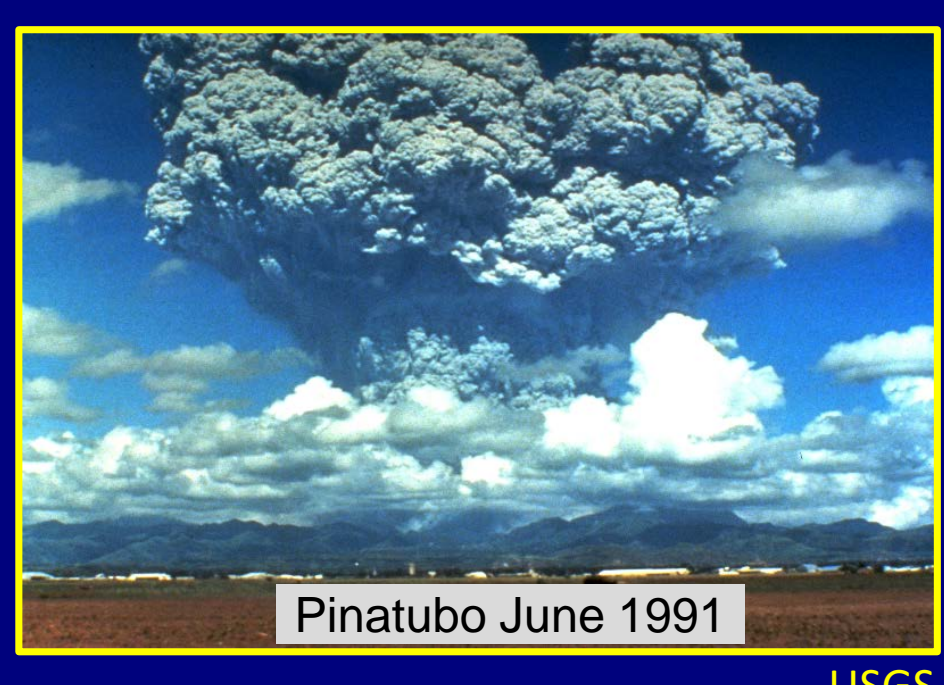
Pinatubo warmed $3.5^{\circ} \mathrm{C}$ Dec 1991 to Feb 1992

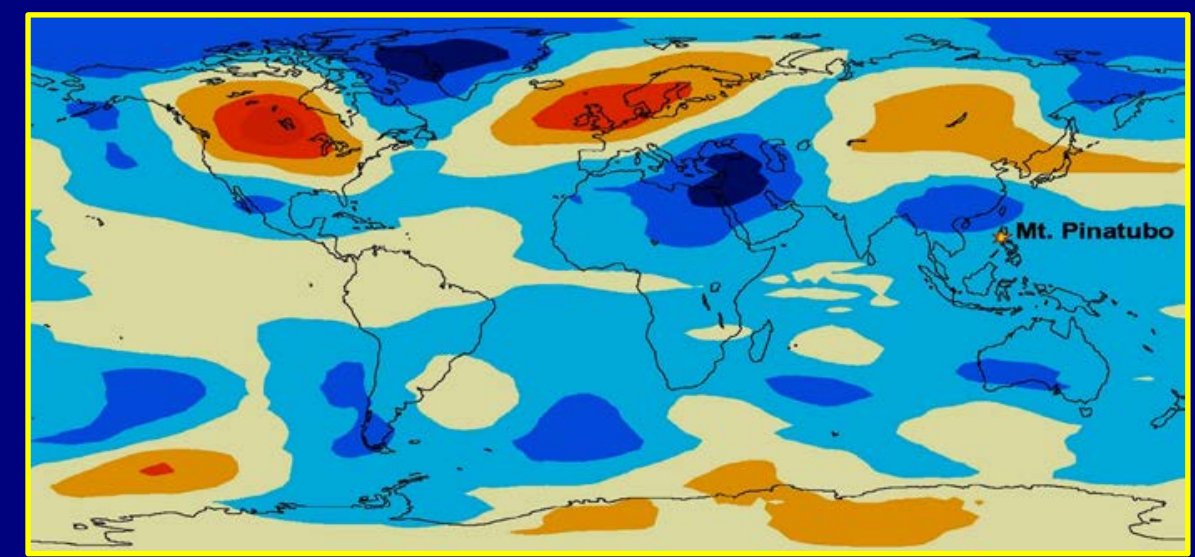




\section{A fundamentally different type of volcanic eruption}

Subduction-related, explosive, volcanic eruptions cool Earth incrementally over centuries

Erupt for days, may recur within 500 to 1000 years Deplete ozone causing short-term warming

Form aerosols in the lower stratosphere that last for years, scattering and reflecting solar energy, causing net global cooling $0.5^{\circ} \mathrm{C}, 3$ years

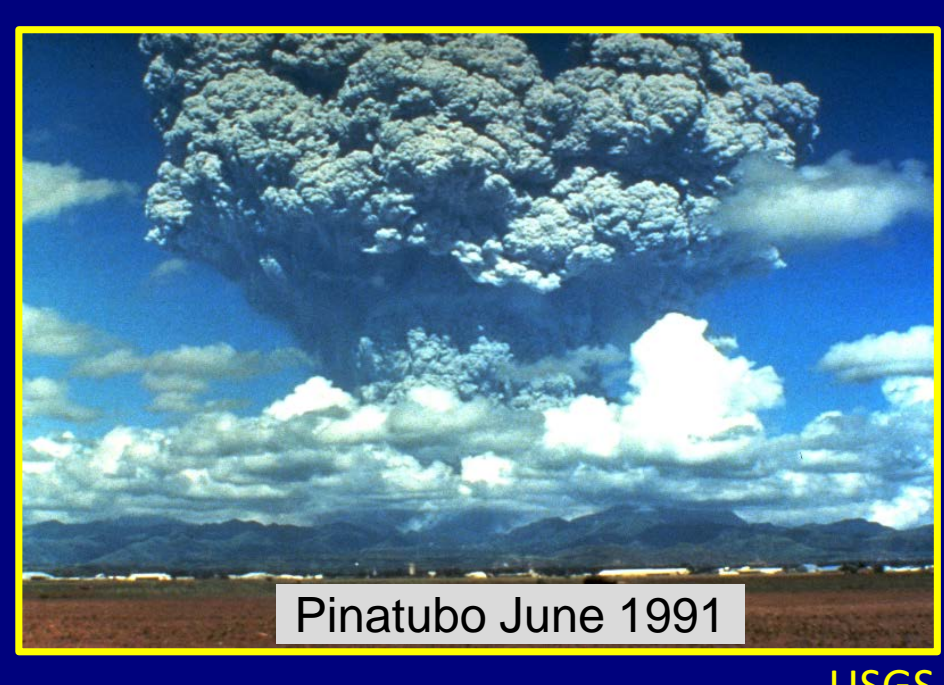

Pinatubo warmed $3.5^{\circ} \mathrm{C}$

Dec 1991 to Feb 1992

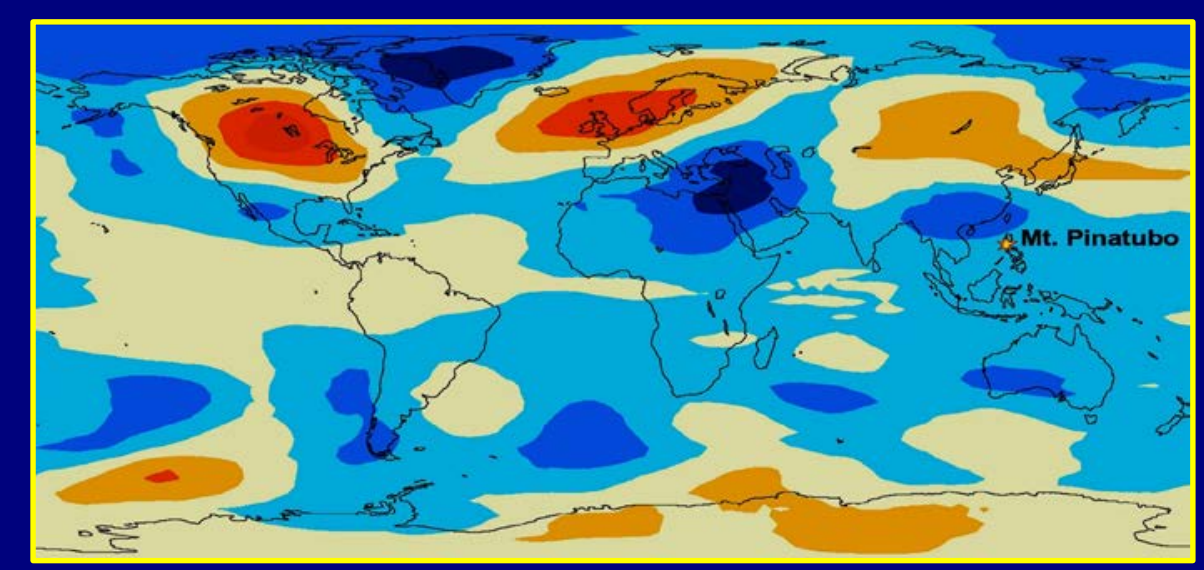

Krakatau (1883) cooled ocean for more than 100 years

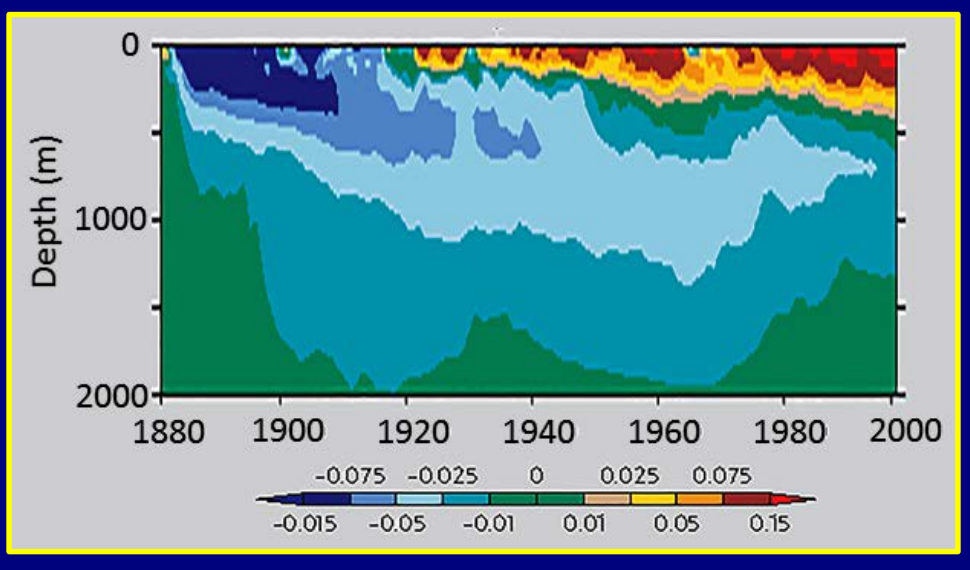




\section{A fundamentally different type of volcanic eruption}

Subduction-related, explosive, volcanic eruptions cool Earth incrementally over centuries

Erupt for days, may recur within 500 to 1000 years Deplete ozone causing short-term warming

Form aerosols in the lower stratosphere that last for years, scattering and reflecting solar energy, causing net global cooling $0.5^{\circ} \mathrm{C}, 3$ years

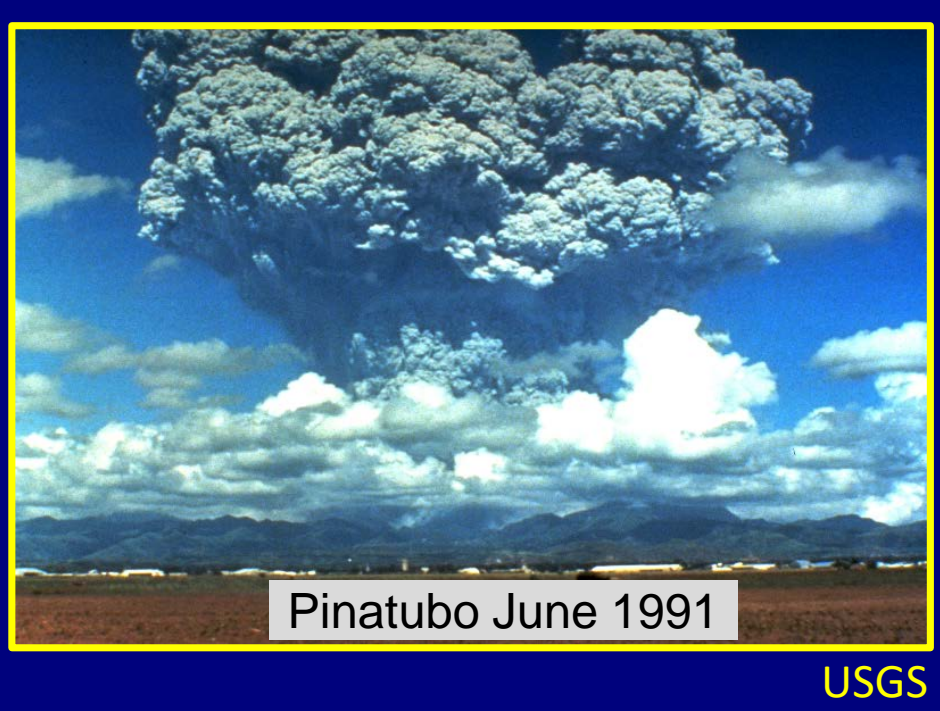

Pinatubo warmed $3.5^{\circ} \mathrm{C}$ Dec 1991 to Feb 1992

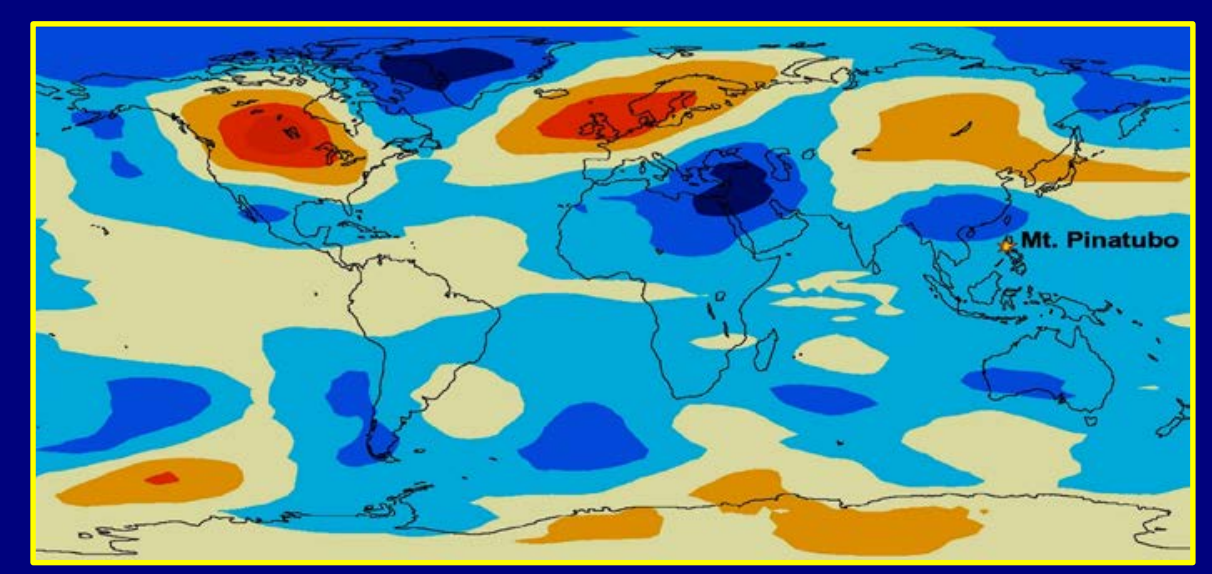

Robock, 2002
Krakatau (1883) cooled ocean for more than 100 years

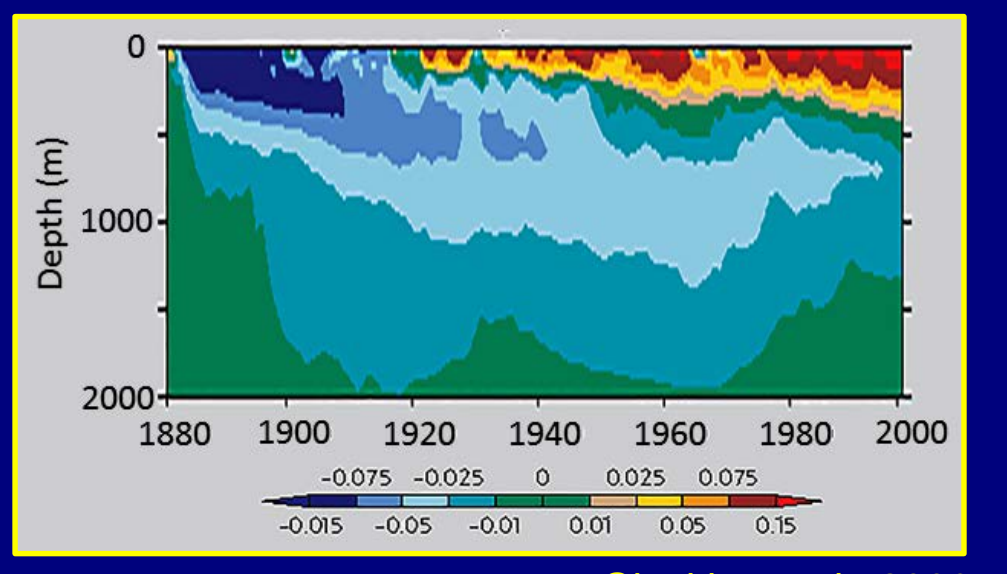

Gleckler et al., 2006
Multiple eruptions increment world into an ice age

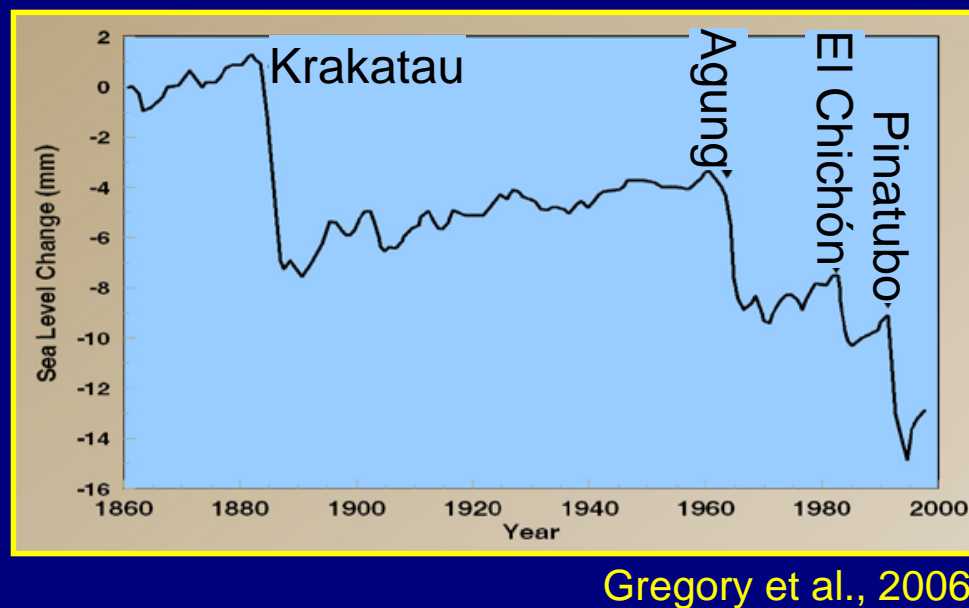




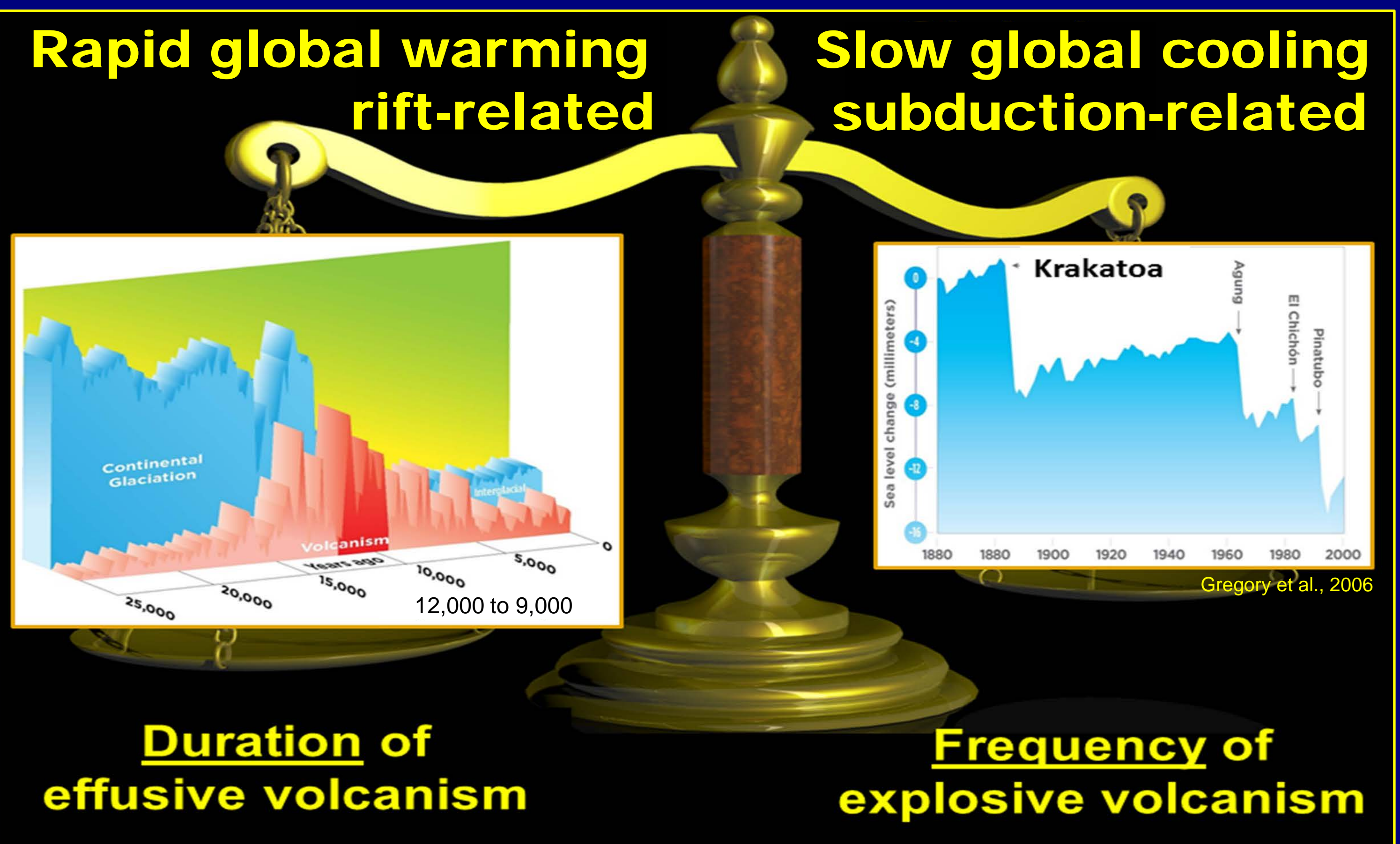


Erratic sequences of rapid warming followed by slower cooling Dansgaard-Oeschger events

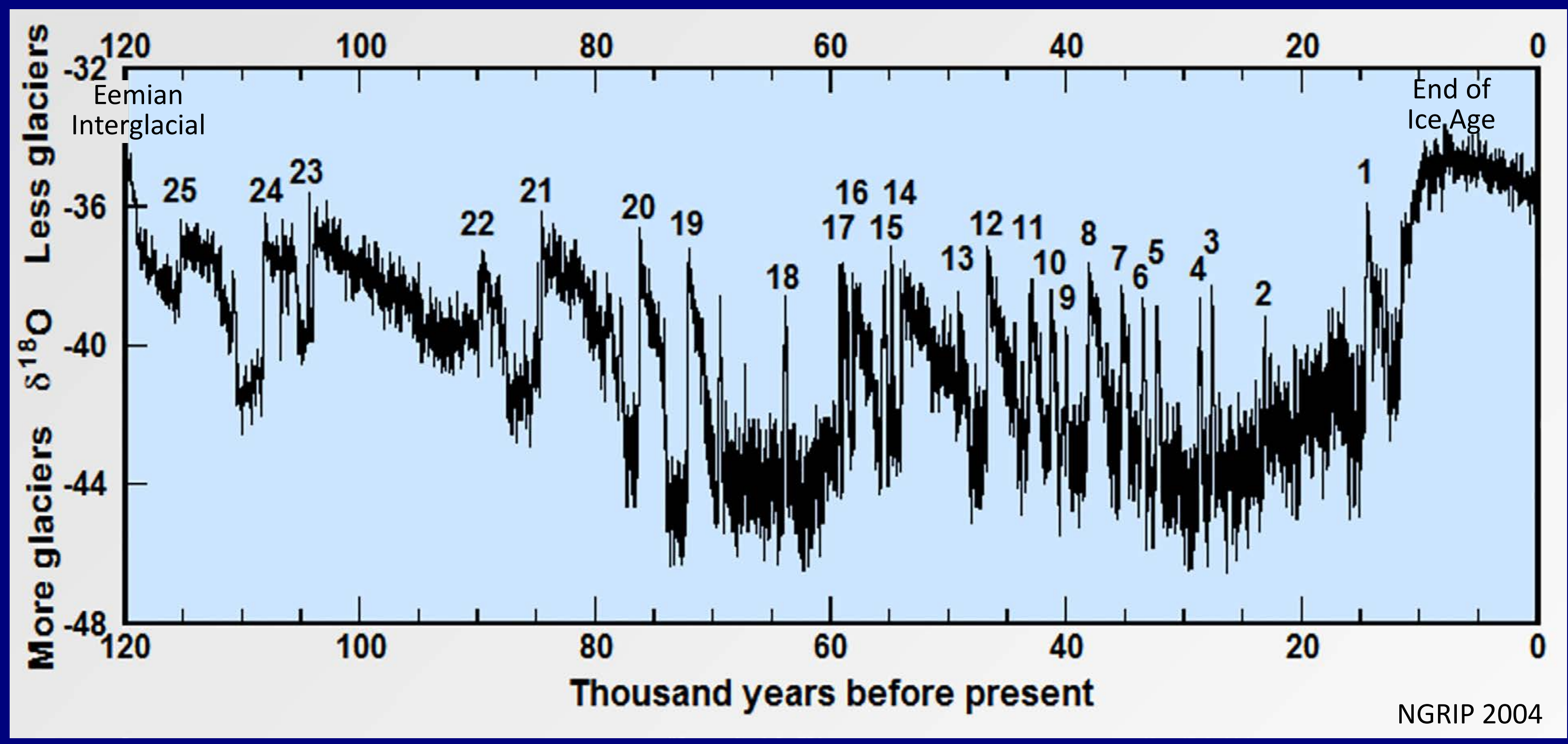


Erratic sudden major warming within a few years followed by cumulative cooling over centuries to millennia

On average, one sequence every 5000 years, but not cyclic

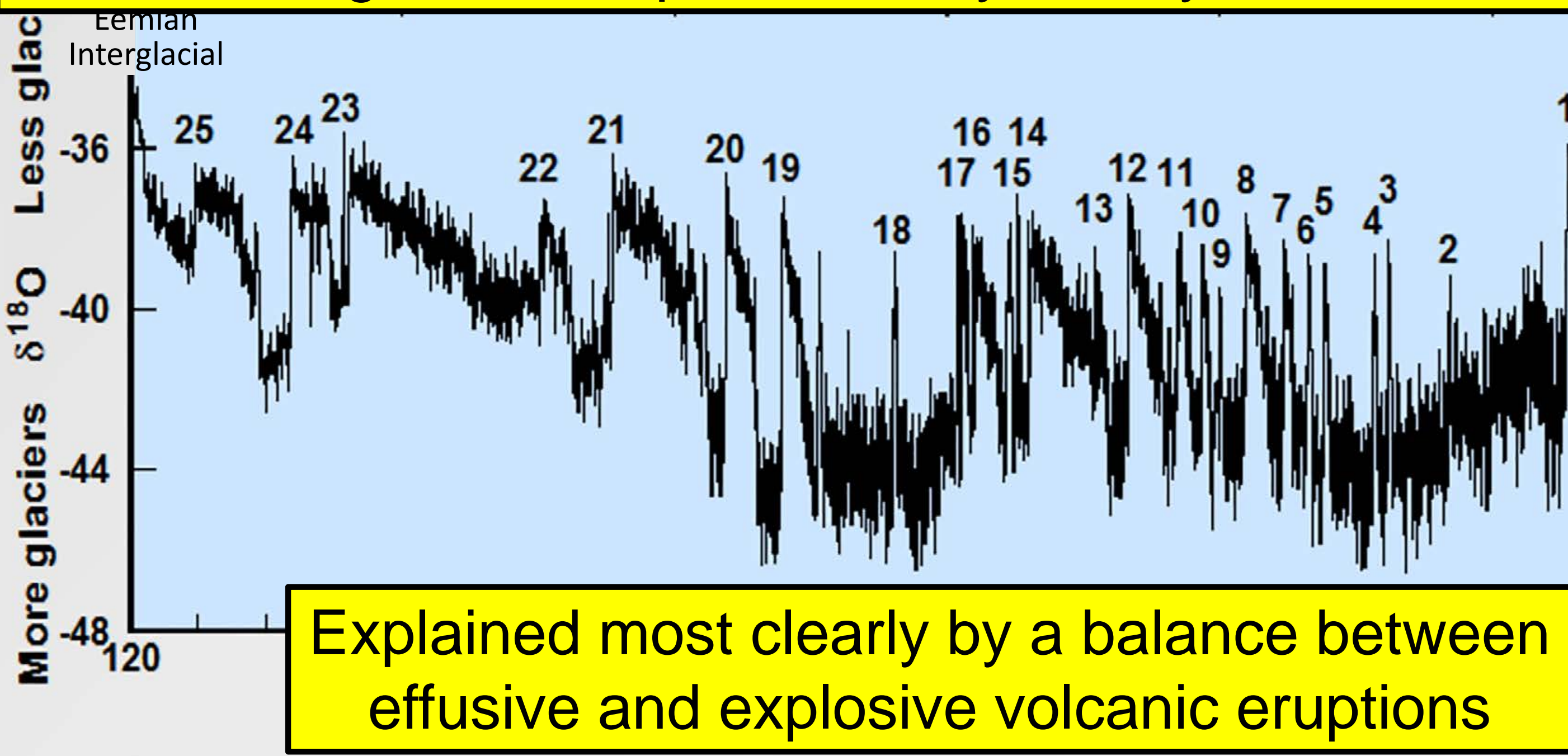
Ice Age in will w.

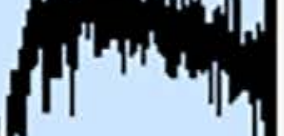




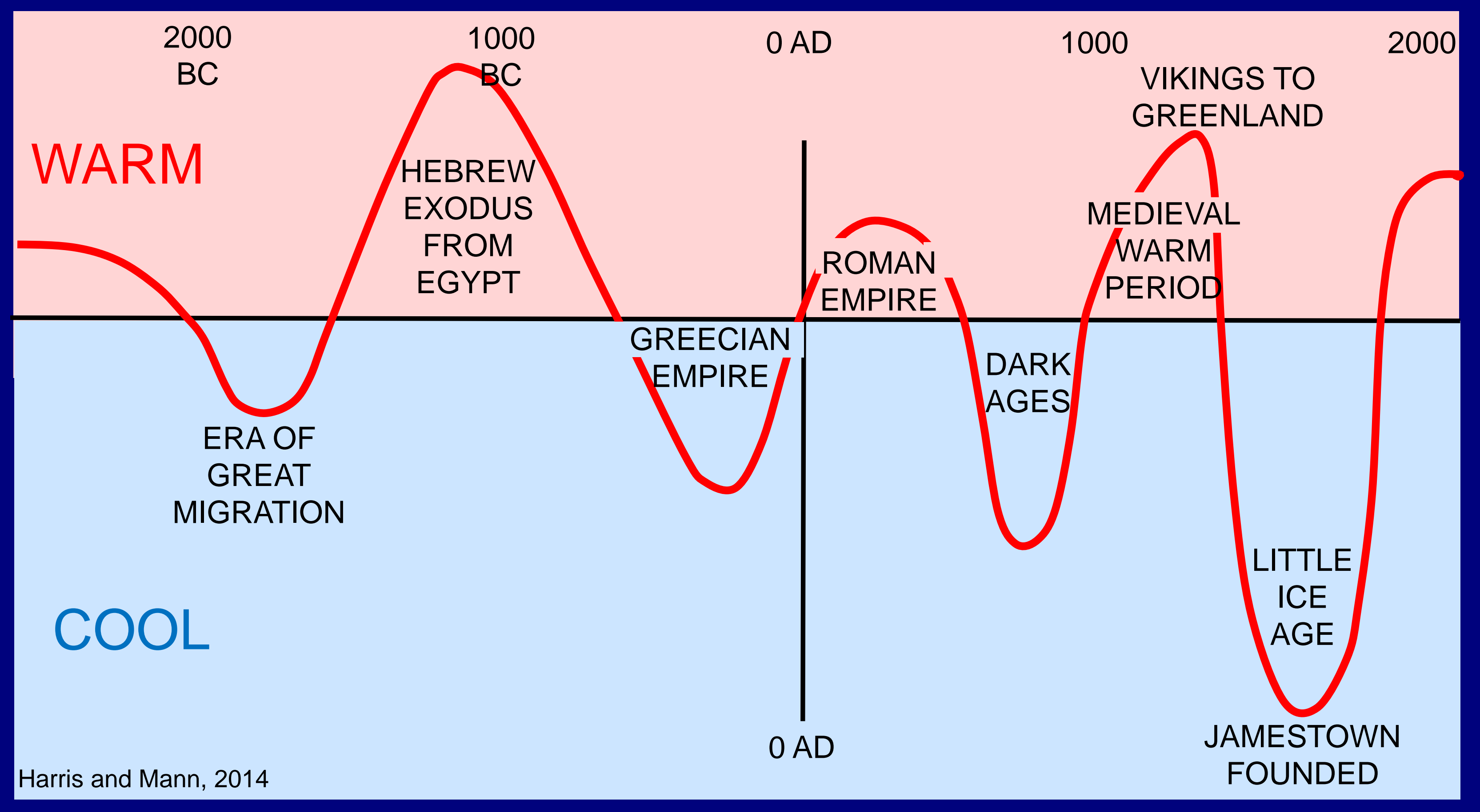




\section{Eocene Green River Formation in Wyoming}

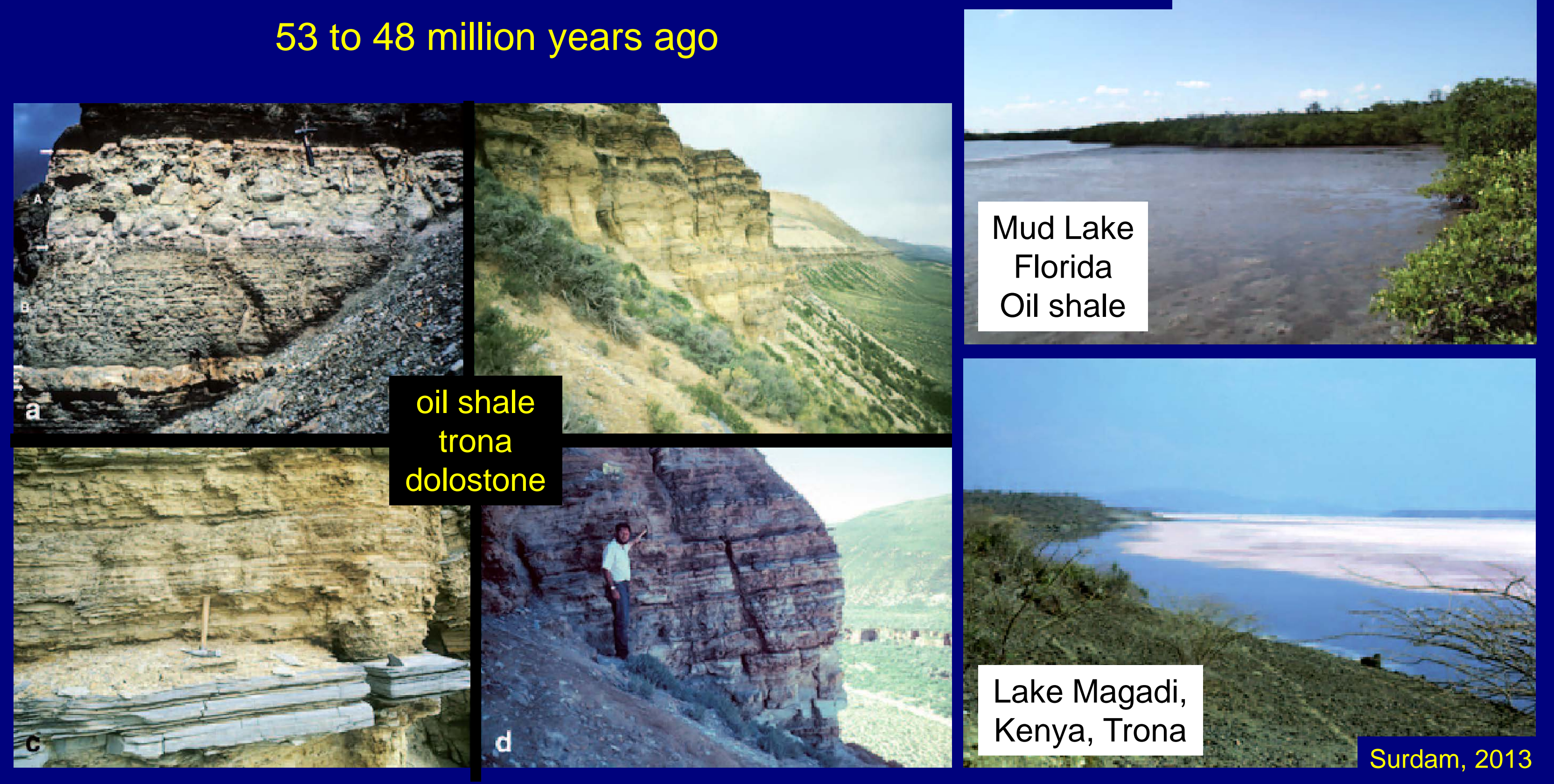




\section{The Footprints of Climate Change}

\section{Sudden warming followed by much slower cooling in erratic sequences averaging 5000 years}

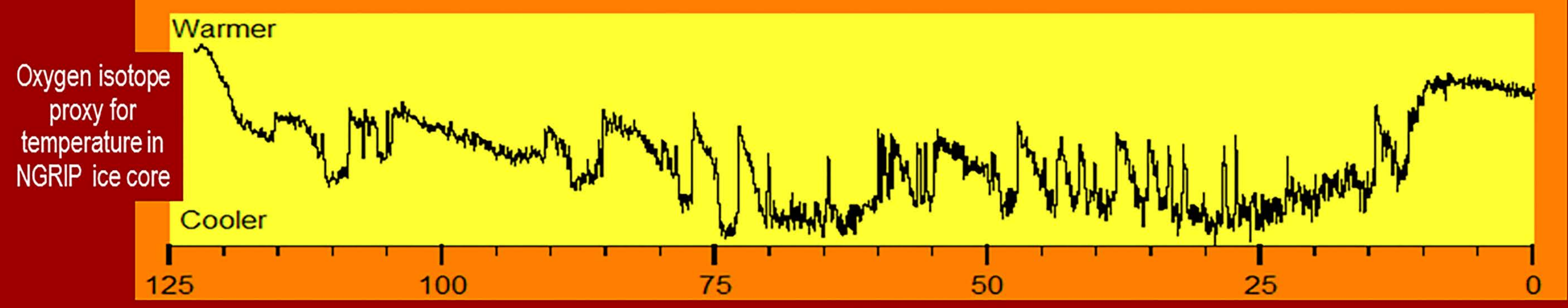

Thousand years before present

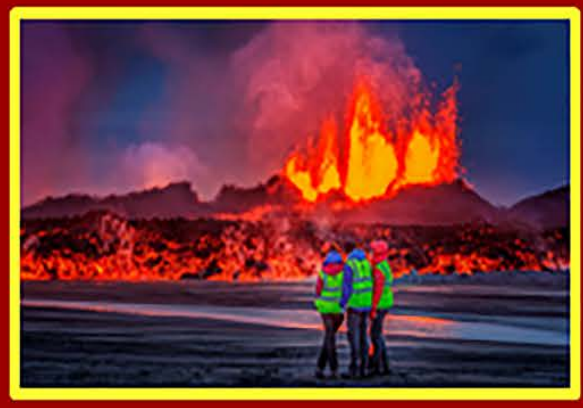

(C) Arctic-Images/Corbis
Large effusive basalt flows cause sudden warming

Bárđarbunga 2014

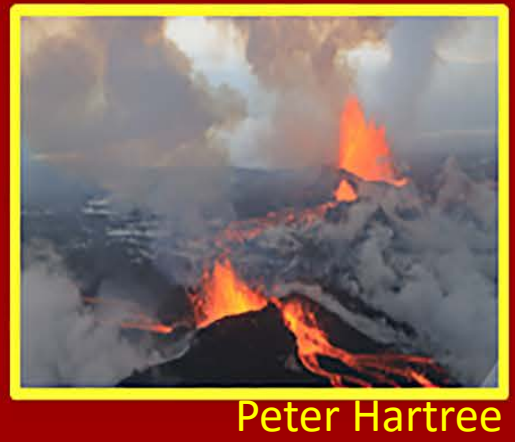

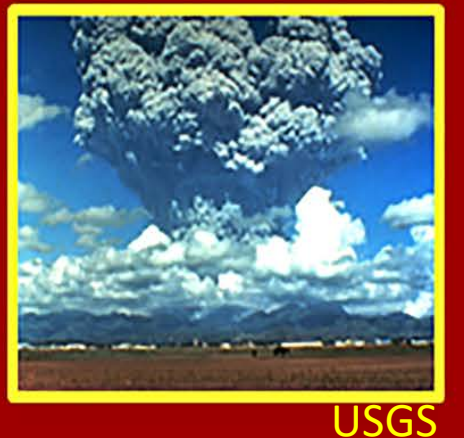

Large explosive volcanic eruptions cause slower cumulative cooling

Pinatubo 1991

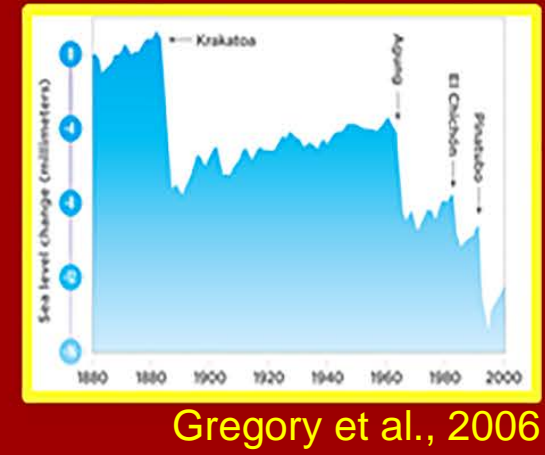




\section{The Footprints of Climate Change}

Sudden warming followed by much slower cooling in erratic sequences averaging 5000 years

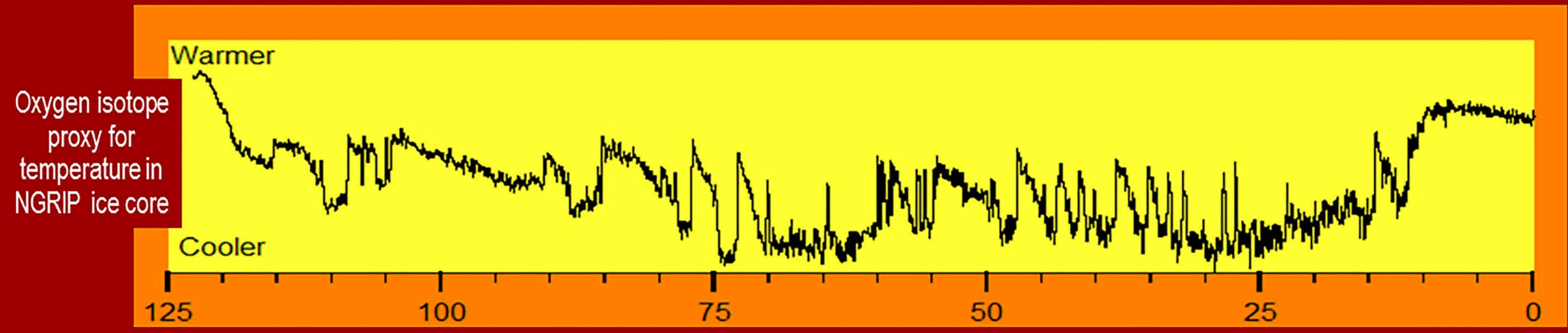

Thousand years before present

\section{How could greenhouse warming cause such footprints?}

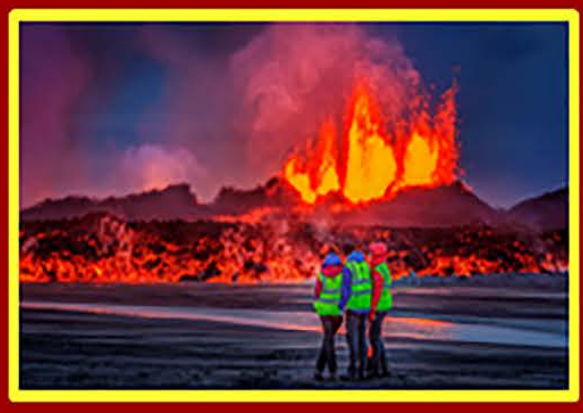

(C) Arctic-Images/Corbis
Large effiusive basalt flows cause sudden warming

Bárđarbunga 2014

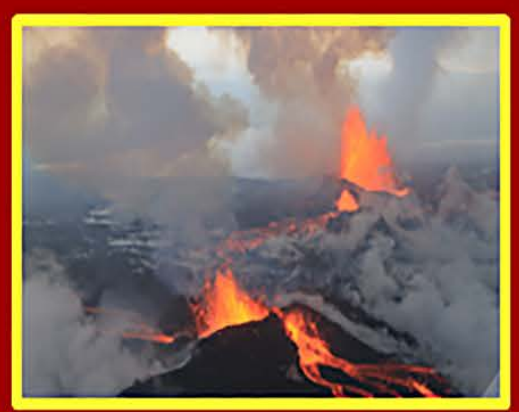

Peter Hartree

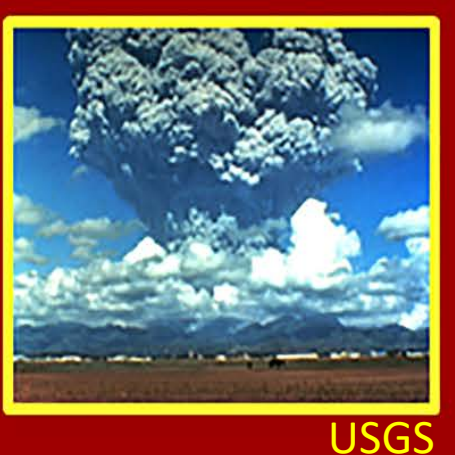

Large explosive volcanic eruptions cause slower cumulative cooling

Pinatubo 1991

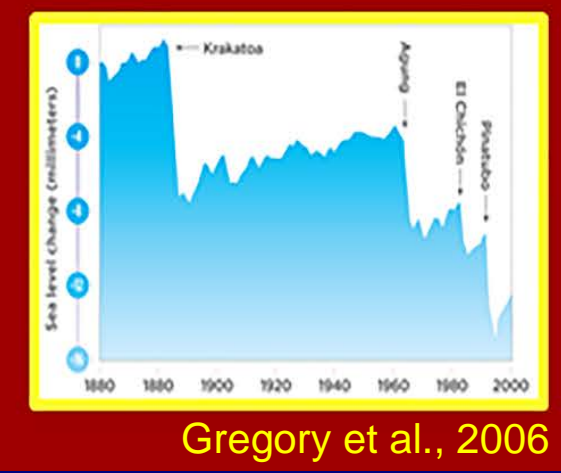




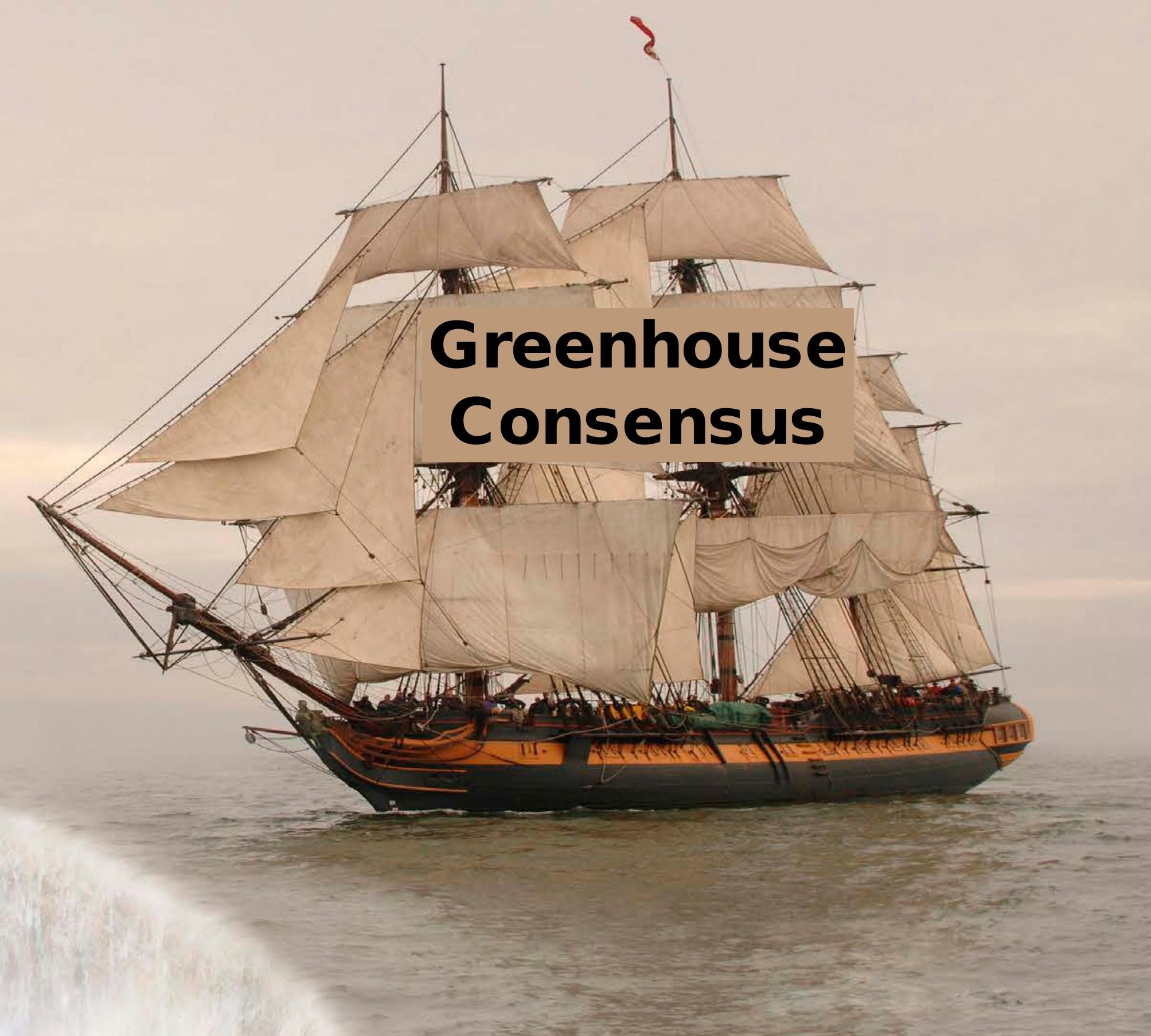


The IPCC has spent 28 years crafting greenhouse cọnsensus

Since Paris, 2015, most nations are preparing to spend $\$ 10,000,000,000,000$ to reduce greenhouse gases

What if this has no effect on global warming?

This could be the greatest economic and political crisis ever created by mistaken science

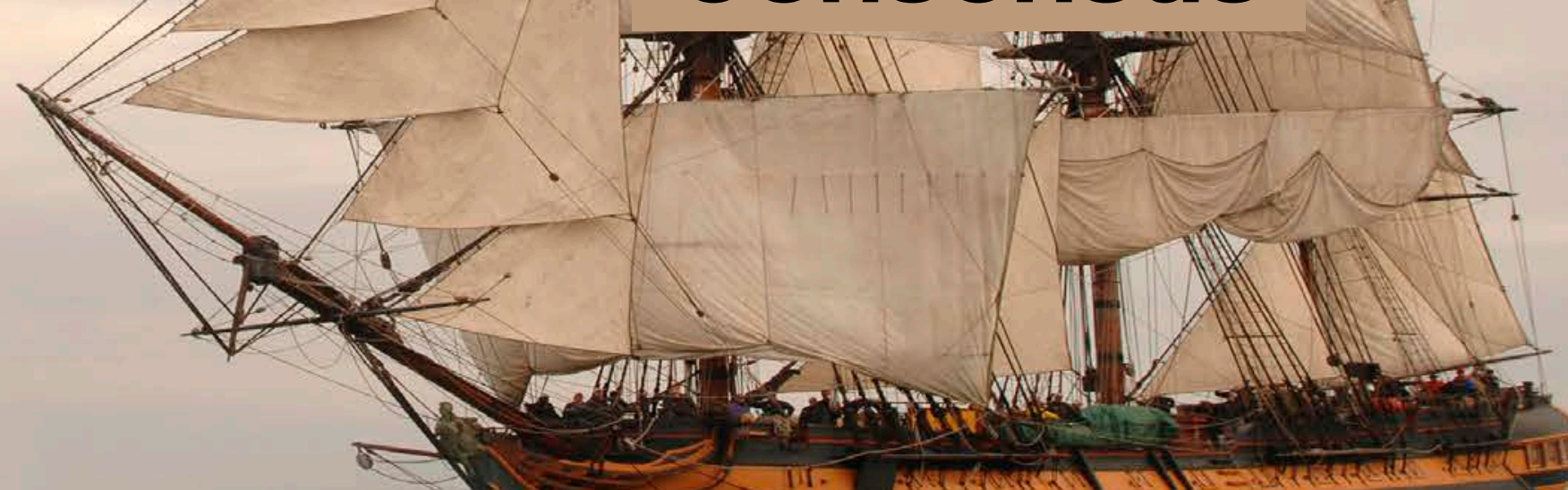

We Earth scientists need to speak up!

We have to get this right

All citizens of the world are depending on us. 
"In science consensus is irrelevant. What is relevant is reproducible results." 
"In science consensus is irrelevant. What is relevant is reproducible results."

I am actively looking for ways to engage people in discussing the footprints of climate change in the geologic record
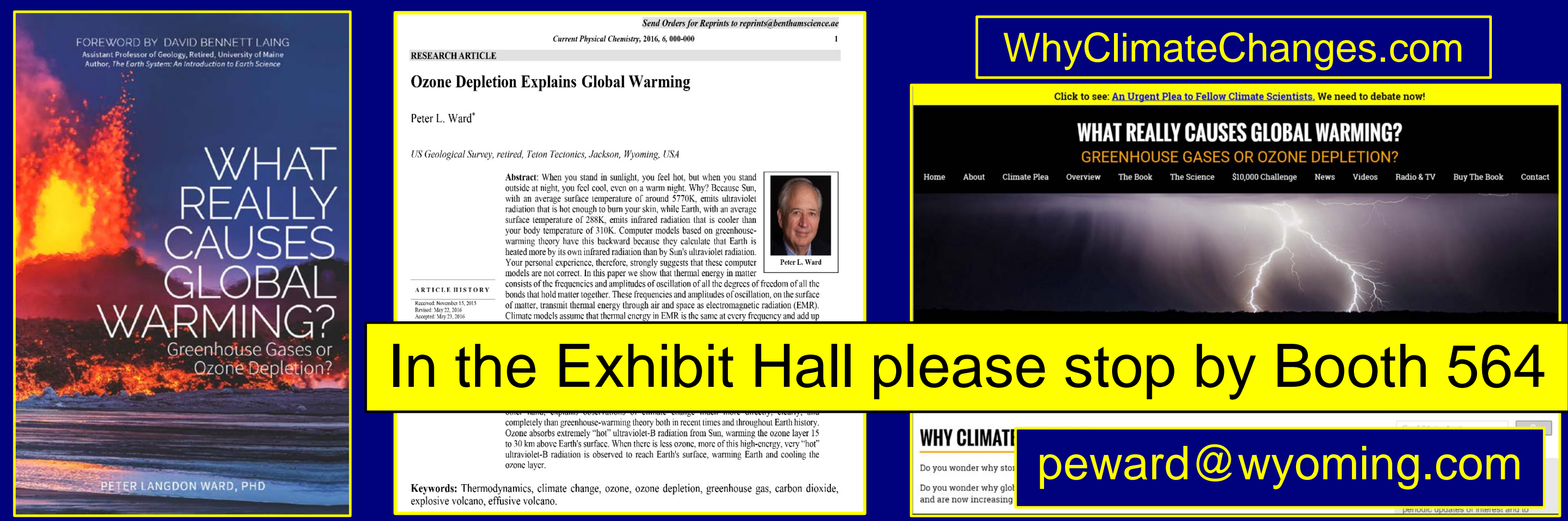

In the Exhibit Hall please stop by Booth 564

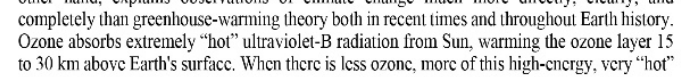

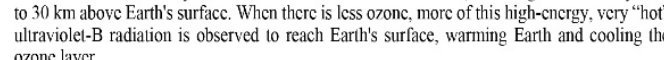

